allergic rhinitis. Am J Rhinol 2006;20: 641-647.

3. Katelaris $\mathrm{CH}$. Allergic rhinitis and asthma: epidemiological evidence for the link. Clin Exp Allergy Rev 2003;3:5-8.

4. Bousquet J, Khaltaev N, Cruz AA, Denburg J, Fokkens WJ, Togias A et al. Allergic Rhinitis and its Impact on Asthma (ARIA) 2008 Update (in collaboration with the World Health Organization, GA2LEN and AllerGen). Allergy 2008;63(Suppl. 86): 8-160.

5. Cirillo I, Pistorio A, Tosca MA, Ciprandi G. Impact of allergic rhinitis on asthma: effects on bronchial hyperreactivity. Allergy 2009;64:439-444.

\section{Toothpaste-induced anaphylaxis caused by mint (Mentha) allergy}

\section{Paiva, S. Piedade, Â. Gaspar*}

Keywords: allergy; anaphylaxis; menthol; mint; toothpaste.

To our knowledge, the present report is the first description of an IgE-mediated anaphylaxis to mint (Mentha piperita) related to the use of toothpaste.

We present a clinical case of a 46-year-old woman, nonatopic and without relevant past medical history, referred to our Immunoallergy out-
We report a rare case of IgE-mediated anaphylaxis after exposure to toothpaste.

\section{patient clinic}

for suspected nonsteroidal anti-inflammatory (NSAIDs) hypersensitivity. The patient had a first episode of anaphylaxis, characterized by generalized urticaria and laryngeal oedema, $30 \mathrm{~min}$ after oral intake of metamizol $575 \mathrm{mg}$ Nolotil $^{\circledR}$, Boehringer Ingelheim, Ingelheim, Germany), in June 2008. She was treated in the emergency room with i.m. epinephrine and i.v. corticosteroid and $\mathrm{H}_{1}$ antihistamine, with regression of the symptoms, and was discharge with indication to avoid metamizol and other NSAIDs. She had three more anaphylactic episodes, after 12 h, 3 and 5 days, respectively. The patient reported a relationship between these episodes and the use of toothpaste Colgate $^{\circledR}$, Colgate-Palmolive, New York, NY, USA, and Sensodyne ProEsmalte $^{\circledR}$, GlaxoSmithKline, London, UK).

At the Immunoallergy Department, a challenge test was performed with Sensodyne Pro-Esmalte ${ }^{\circledR}$ toothpaste use, being strongly positive and characterized by immediate ( $<5 \mathrm{~min}$ ) facial urticaria, abdominal colic and bronchospasm, requiring immediate treatment with i.m. epinephrine. The patient performed skin prick tests (SPT) that were positive to all tested toothpastes (including Colgate ${ }^{\circledR}$ and Sensodyne Pro-Esmalte ${ }^{\circledR}$ ). Consulting the toothpaste's laboratories for further information about the toothpaste's ingredients, menthol was found to be the common 'flavour' probably related to the reactions. The patient performed SPT with $100 \%$ peppermint oil that was strongly positive $(48 \mathrm{~mm}$ mean diameter wheal) and accompanied by symptoms of rhinitis and conjunctivitis. The same skin test was negative in 10 adult atopic controls. Mint-specific IgE measurements by two different methods (UniCAP ${ }^{\circledR}$, Phadia, Uppsala, Sweden; and Immulite ${ }^{\circledR} 2000$, Siemens Healthcare Diagnostics, Deerfield, IL, USA) were negative. SPT and challenge test with a menthol-free toothpaste (Elmex menthol-free ${ }^{\circledR}$, GABA International, Therwil, Switzerland) were both negative. Regardless indication for avoidance of metamizol, 4 months after the first reaction, the patient had a new anaphylactic episode, with loss of consciousness, after administration of i.v. metamizol prescribed for severe pain. The patient performed SPT with metamizol i.v. solution, at a concentration of $0.4 \mathrm{~g} / \mathrm{ml}$, which was positive ( $9 \mathrm{~mm}$ mean diameter wheal). CAST $^{\circledR}$, (Bühlmann, Schönenbuch, Switzerland) to metamizol was negative. Single-blind placebo-controlled oral challenges were performed with etoricoxibe, meloxicam, ibuprofen and diclofenac, being all negative.

There are few reports of IgE-mediated allergy to toothpaste, being mint or its cyclic alcohol derivative menthol, the usual responsible. The first immediate reaction was described in 1964 in a woman with recurrent urticaria after exposure to different menthol-containing products that was reproducible in a challenge with a menthol solution (1). In 1990, Spurlock et al. (2) described a patient with asthma triggered by menthol-containing toothpaste. Since then some other cases were published referring to immediate hypersensitivity to mint or menthol, with different clinical presentation including urticaria, rhinitis and asthma (3-5). After performing challenges with menthol-containing toothpaste, Kawane found a significant decrease in $\mathrm{FEV}_{1}$. The same test was performed in four patients with asthma but no menthol induced symptoms and the result was negative to all. Challenges were negative with menthol-free toothpaste (3).

This is a rare case, with an IgE-mediated anaphylaxis to mint (Mentha piperita) and also an IgEmediated anaphylaxis to metamizol, a pyrazolone drug, often associated with IgE-mediated reactions (6), with tolerance to other NSAIDs. A selfinjectable epinephrine device has been prescribed, as well as avoidance of metamizol, daily use of menthol-free toothpaste and strictly avoidance of mint and menthol-containing products. This case emphasizes the importance of being aware about any possible allergen, even those presumably innocent.

\author{
*Immunoallergy Department \\ Dona Estefânia Hospital \\ Rua Jacinta Marto \\ 1169-045 Lisbon \\ Portugal \\ Tel.: + 351213126653 \\ Fax: + 351213126654 \\ E-mail: angela.gaspar@sapo.pt
}

Accepted for publication 16 December 2009

Allergy 2010: 65:1201-1202

(C) 2010 John Wiley \& Sons A/S

DOI: $10.1111 /$ j.1398-9995.2010.02329.x

\section{References}

1. Papa CM, Shelley WB. Menthol hypersensitivity. JAMA 1964;189:546-548. 
2. Spurlock BW, Dailey TM. Shortness of (fresh) breath-toothpaste-induced broncho spasm. N Engl J Med 1990;323:1845-1846.

3. Kawane H. Menthol and aspirin induced asthma. Respir Med 1996;90:247.

4. Andersson M, Hindsén M. Rhinitis because of toothpaste and other menthol-containing products. Allergy 2007;62:336-337.

5. Marlowe KF. Urticaria and asthma exacerbation after ingestion of menthol-containing lozenges. Am J Health Syst Pharm 2003;60:1657-1659.

6. Himly M, Jahn-Schmid B, Pittertschatscher K, Bohle B, Grubmayr K, Ferreira F et al. IgE-mediated immediate type-hypersensitivity to the pyrazolone drug propyphenazone. $J$ Allergy Clin Immunol 2003;111:882-888.

\section{Anaphylaxis to Raphanus niger}

N. Sousa, Â. Gaspar, M. Morais-Almeida*

Keywords: allergy; anaphylaxis; food supplement; radish; Raphanus niger.

Immunoglobulin E (IgE) mediated food allergy to members of the Brassicaceae family is uncommon. The first case was described in 1980 by Panconesi et al. (1) and was attributed to mustard in a pizza. Since then, several mustard allergy cases have been reported $(2,3)$, being allergic to other

crucifers is

exceedingly

rare, namely to

the Raphanus

gender. To our

knowledge,

This is the first

description of

anaphylaxis to

foodstuff of the

Raphanus gender.

only two cases

of possible

allergic reactions to Raphanus have been reported, one patient with contact dermatitis (4) and another one with acute urticaria (5).

Nowadays, adverse events related with dietary supplements intake are increasingly reported, but the majority of the consumers are not aware of the potential dangers of these natural health products (6).

The authors report the case of a 56-year-old female patient, with a history of nonatopic asthma and allergic rhinitis since childhood. The patient initiated generalized urticaria, facial angioedema, and severe bronchospasm $\left(\mathrm{O}_{2}\right.$ saturation in room air $\left.=88 \%\right)$, $10 \mathrm{~min}$ after the ingestion of a $15 \mathrm{ml}$ ampoule of Hepatocomplex ${ }^{\circledR}$ (Biocol Laboratórios, Alcoitão, Portugal), a food supplement used for weight loss. She was medicated in the emergency room with i.m. adrenalin, as well as i.v. corticosteroid and $\mathrm{H}_{1}$ anti-histamine, with regression of the symptoms. No other food was ingested in the previous hours. There was also no strenuous exercise after the ingestion. The patient had taken this food supplement previously with no adverse reaction.

Skin prick test with Hepatocomplex ${ }^{\circledR}$ was performed. Not only was the skin test positive (5-mm mean diameter wheal), but it was accompanied by dry cough that promptly reverted with inhaled salbutamol. The composition of this food supplement was analyzed to find the culprit foodstuff. It contained rosemary (Rosmarinus officinalis), artichoke (Cynara cardunculus), and black radish (Raphanus niger), as well as sorbitol, glycerin, lecithin, choline, arginine, vitamin E, and several oligoelements. Prick-prick tests with the first three fresh foodstuffs were performed and were clearly positive for the black radish (10.5-mm mean diameter wheal); the remainders were negative; the patient also had a positive prick-prick test (5-mm mean diameter wheal) to radish (Raphanus sativus). The same skin tests were negative in 10 adult atopic controls. The patient has no recollection of purposely eating any type of radish. Ingestion of other members of the Brassicaceae family did not elicit symptoms, namely mustard, broccoli, and cabbages. Avoidance of the Raphanus gender has been indicated, as well as an adrenaline auto-injector was prescribed for possible hidden allergens, taking into account the severe nature of the reaction.

To our knowledge, this report constitutes the first anaphylactic IgE-mediated reaction to foodstuff of the Raphanus gender. Our patient presented a positive skin test with the raw Raphanus niger, as well as Raphanus sativus, a closely related species.
An irritant effect can be ruled out, because the same skin test was negative in 10 atopic controls. Although also suggestive of an IgE-mediated reaction, in the report of Sayed et al. (5), they did not perform skin prick or prickprick tests and only had a late moderately positive scratch test at $40 \mathrm{~min}$. Oral provocation test is formally contra-indicated in our case, given the clear cut history of severe anaphylaxis and positive skin test. Allergy to other constituents of the food supplement was ruled out. Considering the extensive use of herbal and food supplements, a comprehensive risk-benefit analysis including a surveillance system for monitoring the adverse health effects of these products is essential, allowing the identification of unpredictable adverse reactions, namely allergic, which are potentially severe (6).

\author{
*Immunoallergy Department \\ CUF-Descobertas Hospital \\ Rua Mário Botas \\ 1998-018 Lisboa \\ Portugal \\ Tel.: + 351917232267 \\ Fax: + 351210025220 \\ E-mail: mmoraisalmeida@netcabo.pt
}

Accepted for publication 16 December 2009

Allergy 2010: 65:1202

(C) 2010 John Wiley \& Sons A/S

DOI: $10.1111 / \mathrm{j} .1398-9995.2010 .02330 . \mathrm{x}$

\section{References}

1. Panconesi E, Sertoli A, Fabbri P, Giorgini S, Spallanzini P. Anaphylactic shock from mustard after ingestion of pizza. Contact Derm 1980;6:294-295.

2. Rancé F, Kanny G, Dutau G, MoneretVautrin DA. Food hypersensitivity in children: clinical aspects and distribution of allergens. Pediatr Allergy Immunol 1999;10:33-38.

3. Rancé F. Mustard allergy as a new food allergy. Allergy 2003;58:287-288.

4. Mitchell JC, Jordan WP. Allergic contact dermatitis from the radish, Raphanus sativus. $\mathrm{Br}$ J Dermatol 1974;91:183-189.

5. Sayed F, Manzur F, Marguery MC, Bayle P, Bazex J. Urticarial manifestations due to Raphanus niger. Contact Derm 1995; 32:241.

6. Ernst E. Herbal medicines: balancing benefits and risks. Novartis Found Symp 2007; 282:154-167. 